\title{
Magnetic resonance imaging of the optic nerve in extremes of gaze Implications for the positioning of the globe for retrobulbar anaesthesia
}

Christopher Liu, Bryan Youl, Ivan Moseley

Abstract

Moorfields Eye Hospital, City Road, London EC1V 2PD

C Liu

I Moseley

The National Hospital for

Neurology and

Neurosurgery, Queen

Square, London

WC1N 3BG

B Youl

I Moseley

Correspondence to:

Mr C S C Liu, Moorfields Eye Hospital, City Road, London ECIV 2PD

Accepted for publication 17 July 1992
Orbital magnetic resonance imaging was carried out in nine directions of gaze in a normal subject. The findings are presented and discussed especially in relation to retrobulbar injections. Atkinson's position is confirmed to be hazardous and a new position for the globe at retrobulbar injections is suggested.

(Br F Ophthalmol 1992; 76: 728-733)

With the advent of day case surgery, a larger proportion of intraocular surgery will be performed under local anaesthesia.' Though cataract surgery could be performed with peribulbar or even subconjunctival anaesthesia alone, many surgeons in Great Britain and in the United States still use a retrobulbar block.

As retrobulbar anaesthesia involves blind insertion of a needle it is not surprising that accidental damage to orbital structures should occur from time to time. The possible complications of retrobulbar injections are well known and range from perforation of the globe, retrobulbar haemorrhage, and injection into or occlusion of orbital vasculature, to damage to the optic nerve $(\mathrm{ON}) .^{3-5}$ The latter is probably much more common than is recognised as it is not routinely looked for. However, the most hazardous complication is injection of anaesthetic agents into the subdural space of the optic nerve,

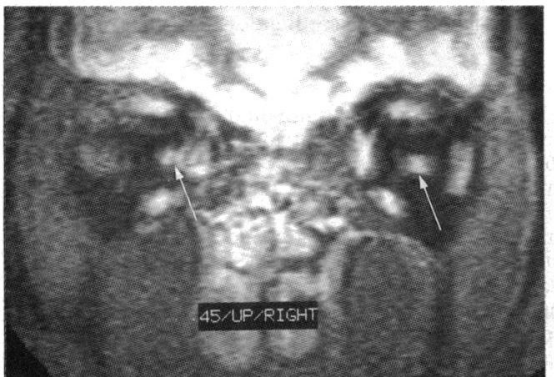

Fig $1 A$

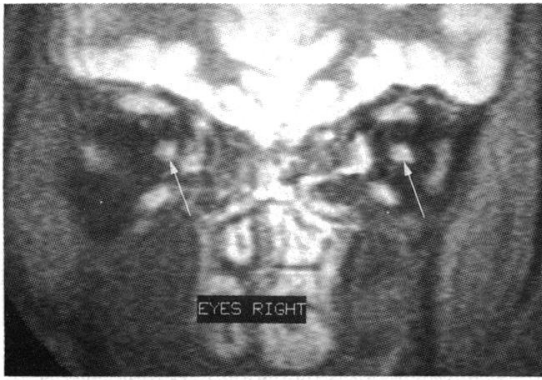

Fig $1 B$

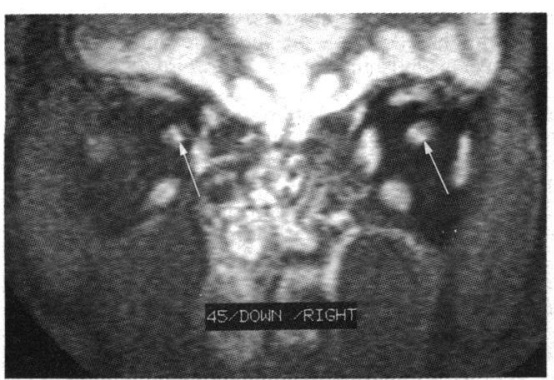

Fig $1 C$

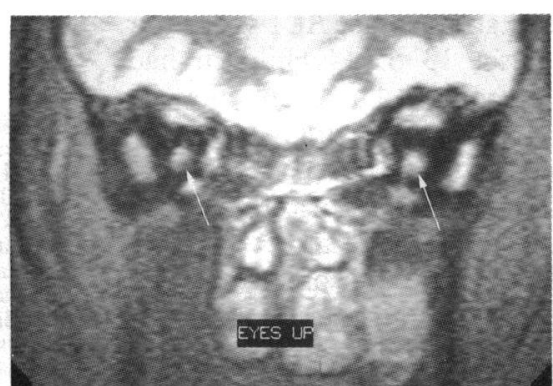

Fig $1 D$

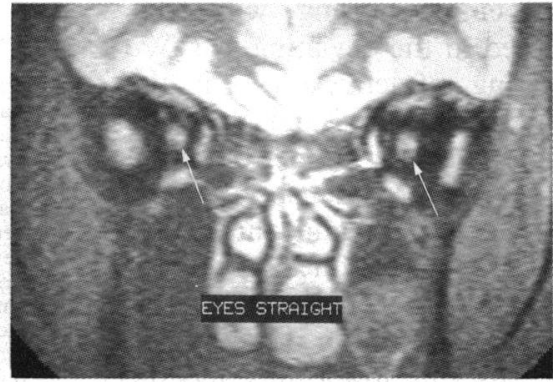

Fig $1 E$

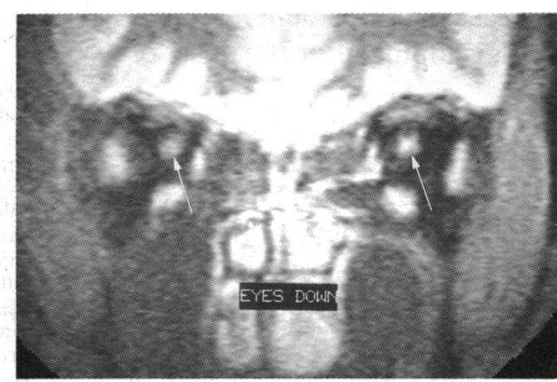

Fig $1 F$

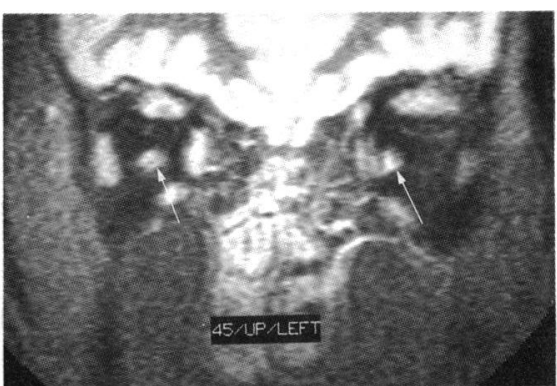

Fig $1 G$

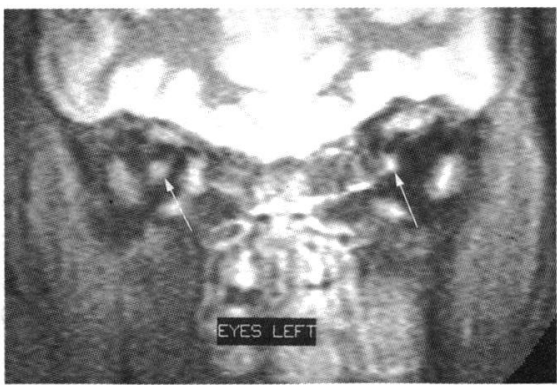

Fig $1 H$

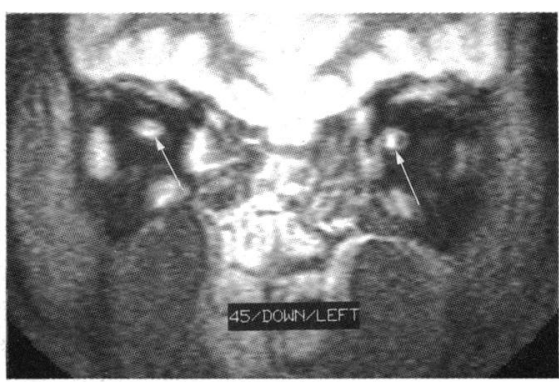

Fig 11

Figure 1 Coronal views of mid orbit with the eyes in: $(A)$ dextro-elevation; $(B)$ dextroversion; $(C)$ dextro-depression; $(D)$ direct upgaze; $(E)$ primary position; $(F)$ direct downgaze; $(G)$ laevo-elevation; $(H)$ laevoversion; $(I)$ laevo-depression. (Arrow=optic nerve). 


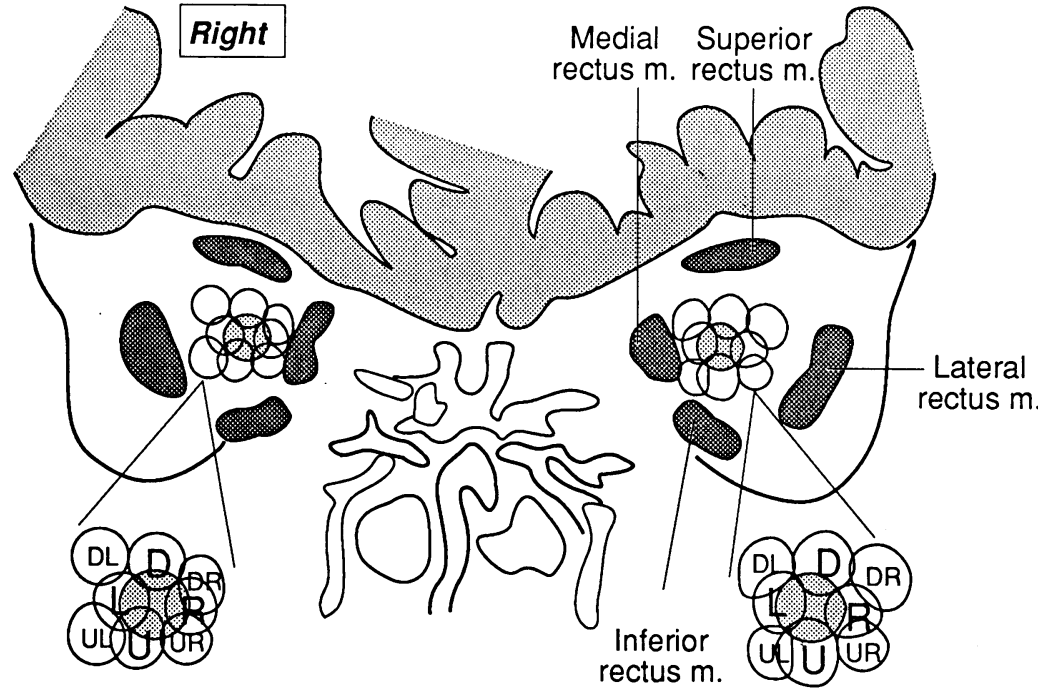

Figure 2 Composite tracing of coronal sequences.

causing potentially lethal brain stem anaesthesia. ${ }^{5-7}$

It has been suggested by many authors that Atkinson's position (looking upwards and nasally $)^{89}$ poses an unnecessary threat to the optic nerve by placing it in close proximity to the needle path. ${ }^{2 \dashv 10}$ This danger was first shown radiologically by Unsöld $e t$ al in a cadaver with the eyes held in position by traction sutures."

As it is now possible to image the excursions of the optic nerve without exposing the subject to ionising radiation, ${ }^{12}{ }^{13}$ we decided to repeat Unsöld's experiment in vivo using magnetic resonance imaging (MRI).

\section{Methods and materials}

T1-weighted inversion recovery sequences with short inversion times (STIR) (IR2000/40/150) were employed on a Picker 0.5 Tesla imager with a surface coil and two signal averages, using $5 \mathrm{~mm}$ slice thickness. Pilot views in three planes allowed coronal, transverse, and paraxial scanning, aligned with respect to the right optic nerve.

The normal subject was first scanned with eyes in the primary position. He was then asked to fixate in eight directions of gaze for coronal sequences, up and down for paraxial sequences, and left and right using transverse sequences.

The use of STIR imaging enables visualisation of orbital structures, with suppression of signal from the orbital fat. ${ }^{11}$

\section{Results}

In the primary position the $\mathrm{ON}$ lies within the muscle cone, a little closer to the medial rectus muscle (MR) (Fig 1E, 2). It assumes a sinuous course (Figs 3B and 4). The sinuous course of the nerve is further demonstrated in horizontal views (Fig 5B), with the nerve coming in and out of the plane of a $5 \mathrm{~mm}$ slice.

In upgaze, the optic nerve moved down and straightened out (Fig 1D, 2, 3A and 4). The superior rectus muscle (SR) thickened as it contracted, and the inferior rectus muscle (IR) thinned out as it relaxed (Figs 1D and 3A).

The reverse occurred on downgaze with one

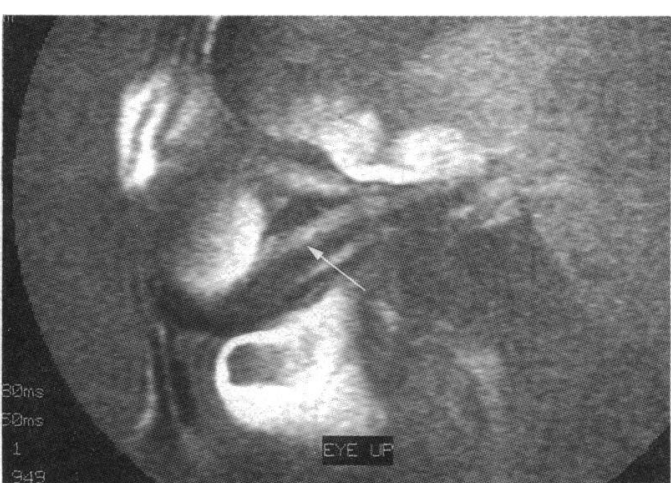

Fig $3 A$

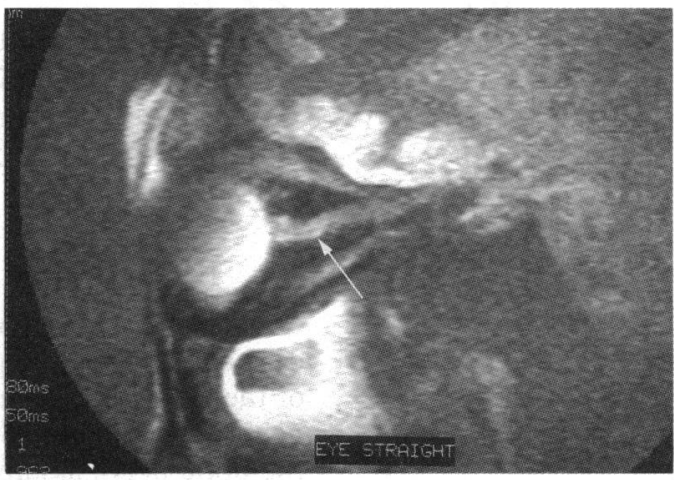

Fig $3 B$

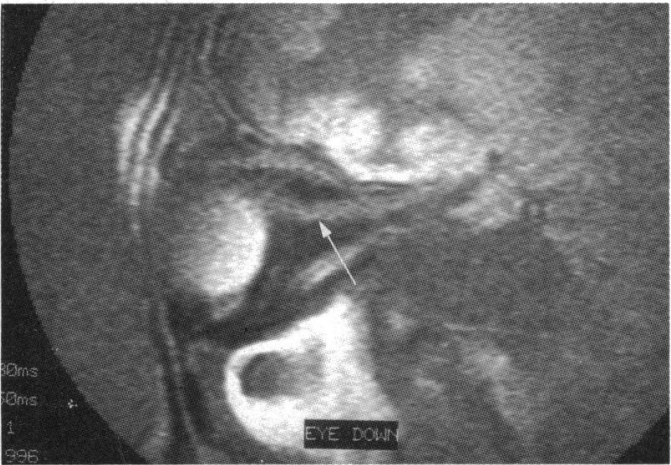

Fig 3C

Figure 3 Paraxial views of right orbit with the eye in:

$(A)$ direct upgaze. $(B)$ primary position. $(C)$ direct downgaze. (Arrow =optic nerve.)

important difference (Figs 1F, 2, 3C, and 4): the nerve took up an S-shaped curve (Figs 3C and 4).

When looking left the nerve moved to the right. The thickening and thinning of the horizontal recti were apparent. The reverse was true with right gaze. The nerve was straightened in adduction (right nerve on left gaze and left nerve on right gaze), but adopted an S-shaped curve on abduction (Fig 5 and 6).

It can be seen in the composite traces of the paraxial and horizontal views that the anterior parts of the nerves move large distances whereas the posterior parts stay relatively still (Figs 4 and 6).

With oblique gaze, two adjacent muscles thicken and the nerve moves away from the direction of gaze (Figs 1A, C, G, I, and 2).

\section{Discussion}

Using MRI we have been able to image the orbits 


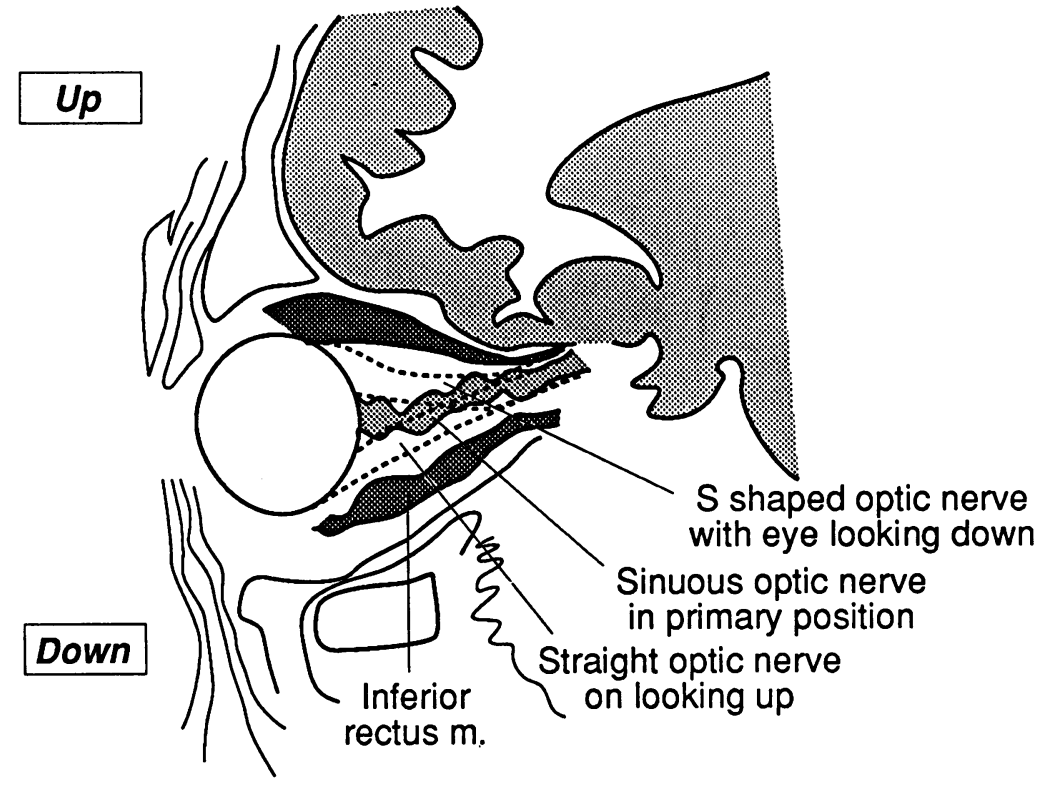

Figure 4 Composite tracing of paraxial sequences. of a normal subject with the eyes in the nine cardinal positions of gaze. Clear differentiation of the globe, extraocular muscles, and the optic nerve was possible. We have demonstrated that the optic nerve assumes a sinuous course when the eye is in the primary position (Figs $3 \mathrm{~B}, 4$, $5 B)$. This is not surprising, as the intraorbital part of the optic nerve is $25-30 \mathrm{~mm}$ long, and the distance it has to traverse is only $18 \mathrm{~mm} .{ }^{15}$ The excursion of the optic nerve with eye movement away from the direction of gaze is also expected (Table 1), though systematic imaging of the orbit with eyes in all different gaze positions had never been reported previously.

Though we have only imaged one subject, we have shown that the optic nerve straightens in both adduction (Figs 5 and 6 ) and upgaze (Figs $3 \mathrm{~A}$ and 4 ), but unexpectedly assumes an $\mathrm{S}$ shaped curve on both abduction (Figs 5 and 6) and downgaze (Figs 3C and 4). This has not been described previously. An S-shaped optic nerve in abduction was also shown by Nishida et al, especially when the 'fixed eye' method was used. ${ }^{13}$ There may be two reasons for the nerve adopting this shape. Firstly, the optic canal is directed forwards, slightly downwards and about $35^{\circ}$ laterally. This inferolateral course is continued by the posterior optic nerve, which turns slightly medially. ${ }^{16}$ In adduction, or in upgaze, the nerve moves closer to the plane of the canal, but in abduction and downgaze, the nerve is forced to bend in the reverse direction. With
Table 1 Summary of findings

The optic nerve shifts against the direction of gaze.

The extent of the excursion of the anterior part of the optic nerve on extreme gaze is large.

There is very little movement of the posterior part of the optic nerve.

The optic nerve takes on an S-shaped curve on temporal gaze and down gaze.

On nasal gaze and on upgaze, the optic nerve becomes straight as though it were stretched.

On oblique gaze, the optic nerve shifts to opposite corner, creating a relatively large stretch of intraconal space which is nerve free.

Outside the primary position, the contracting rectus muscle thickens, with thinning of the antagonistic muscle.

very little space at the apex of the orbit and with the optic nerve having a certain rigidity, it may not be possible for the nerve to turn sharply and therefore an S-shape is created. Secondly, Sevel has shown that at their origins, the SR and MR fuse with the dura mater of the optic nerve. ${ }^{17}$ These attachments may also have some relevance in the shaping of the optic nerve in extreme gaze.

IMPLICATION FOR RETROBULBAR INJECTIONS AND SUGGESTION FOR A NEW TECHNIQUE

It is now generally believed that brain stem anaesthesia results from inadvertent injection of anaesthetic agents into the subdural space of the optic nerve. ${ }^{5-7}$ Drysdale demonstrated this experimentally in a fresh cadaver. Migration of contrast medium along the subdural space of the optic nerve posteriorly to the chiasm, and eventually into the subdural space surrounding the pons and midbrain was shown radiologically. ${ }^{18}$ Though the lipophilic anaesthetic agents may diffuse in a different manner from hydrophilic contrast medium, support for this mechanism comes from the recovery of anaesthetic agents in the cerebrospinal fluid following accidental brain stem anaesthesia. ${ }^{19}$ Once the anaesthetic agent has gained access into the subdural space, it is free to diffuse to affect any part of the central nervous system. ${ }^{2}{ }^{1020-23}$

Historically, Atkinson suggested positioning the globe looking up and nasally for injection of anaesthetic agents into the muscle cone. His reason for recommending this position was that the inferior oblique muscle and the intermuscular septum between the IR and LR would move forward, out of the way of the needle path. ${ }^{89} \mathrm{It}$ has been suggested by many authors that the

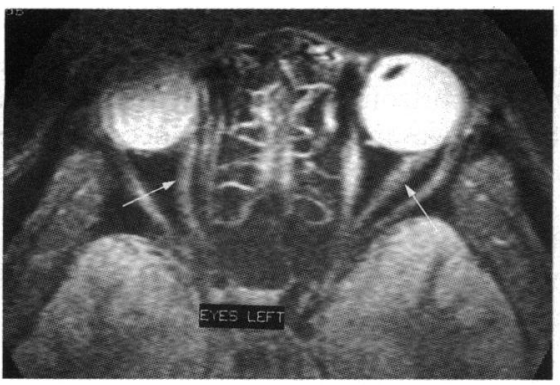

Fig 5 A

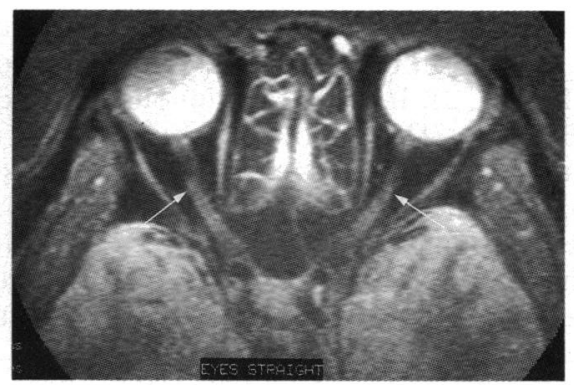

Fig $5 B$

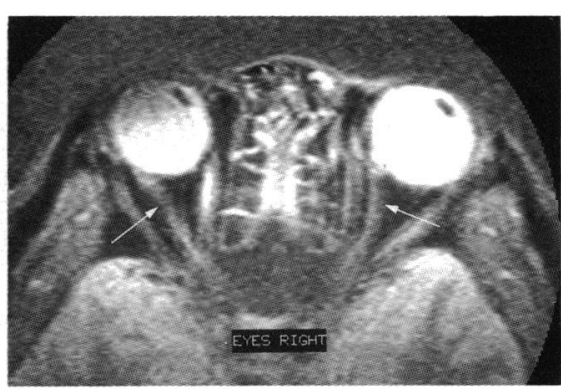

Fig 5C

Figure 5 Horizontal views of both orbits. (A) laevoversion. (B) primary position. $(C)$ dextroversion. (Arrow=optic nerve.) 


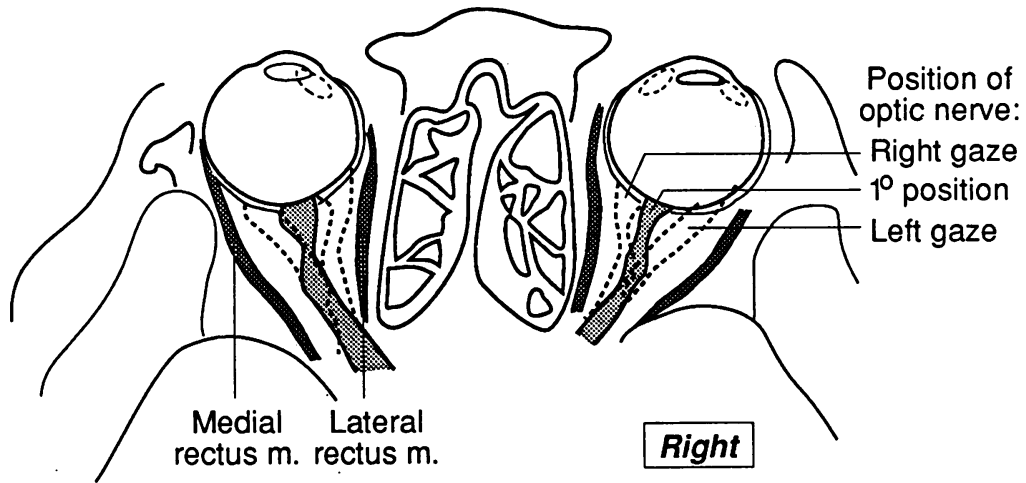

Figure 6 Composite tracing of horizontal sequences. is furthest away from the needle path with the eye looking down and out (Fig 2). However, we have reservations about using this position for retrobulbar injection for two reasons. Firstly, the patient may become frightened at the sight of the needle, especially since we are extracting cataracts earlier nowadays. Furthermore, the cornea will actually get in the way (Fig 7A). These reasons limit the practicality of the down and out position, and it may be for these reasons that the very authors recommending this position also suggest the primary position as a safe alternative. ${ }^{+10}$

An even safer compromise would be the down and in position (Figs 7B and 8). With the patient looking straight ahead, the surgeon places two fingers on the lateral part of the inferior orbital rim. The patient is then asked to look down and nasally at his/her own finger. The surgeon's fingers lift the globe, creating space for entry of the needle (Fig 8). A dimple is also created encouraging a posterior entry site, enabling the needle to avoid the equatorial bulge of the globe (Fig 8). As the entry site is quite posterior, the needle need only be advanced a short distance into the intraconal space. Descent of the upper eyelid is inevitable in downgaze but does not pose a real problem to retrobulbar injection (Fig 7B); after all, direct visualisation of the front of the globe in itself does not guarantee avoiding perforation of the sclera posteriorly.

Though there has been a tendency to move away from retrobulbar anaesthesia, it is still the method practised by the majority of surgeons. ${ }^{2}$ Peribulbar injections are increasingly used but have disadvantages and are not entirely free from complications. ${ }^{24-27}$ Other authors have gone to the trouble of using a sub-Tenon's approach into the intraconal space. ${ }^{28}$ Curved retrobulbar needles have also been designed in an attempt to minimise the risk of complications from retrobulbar anaesthesia. ${ }^{2+29-30}$ Others have operated successfully using a subconjunctival injection alone, ${ }^{31-33}$ though this technique has not gained popularity, presumably because of surgeons' fear of lack of akinesia.'

In an editorial, Lichter pointed out that there are as many variations on the technique of retrobulbar injections as there are surgeons. Surgeons are loath to accept somebody else's technique. ${ }^{3+}$ However, there is now no doubt

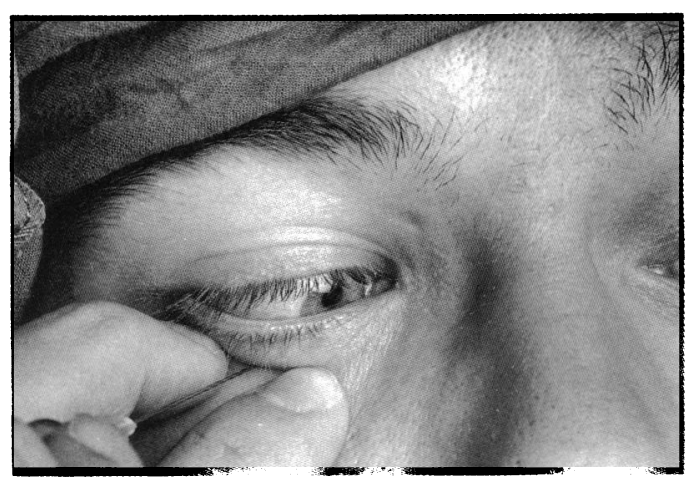

Figure 8 The globe is lifted by placing two finger tips on the lateral part of the inferior orbital margin. The dimple thus created allows a posterior entry site, enabling the needle to avoid the equatorial bulge of the globe.
Figure 7 Lid topography on downgaze. (A) PseudoMunson's sign prevents safe entry of retrobulbar needle. $(B)$ The down and in position (Liu's position.). 
that Atkinson's position is unsafe and there are medicolegal implications. It is therefore surprising to find that this position is still introduced as the standard technique. ${ }^{35}$

The downwards and inwards position presently advocated also moves the major orbital vessels out of the way. The risks of injecting into these vessels or causing a retrobulbar haemorrhage are therefore theoretically lower. It has been pointed out that the patient must keep the eye still while the needle is in place otherwise the bevel of the needle will act as a blade, slicing through tissues, increasing the risk of a haemorrhage. ${ }^{3}$ The relative contraindications to local anaesthesia (long axial length, only eye, uncooperative patient, deafness, language problems, and possibly anticoagulation) still apply to this new technique.

The danger of Atkinson's position is relevant to other retrobulbar injections as well. Retrobulbar botulinum toxin $\mathrm{A}$ injections have been used for the treatment of acquired nystagmus to improve vision by decreasing oscillopsia ( $\mathrm{Mr} \mathrm{J} \mathrm{P}$ Lee, personal communication) ${ }^{36}$ Corticosteroids are less frequently injected into the retrobulbar space but are still occasionally used. ${ }^{37}$ Even less used are retrobulbar alcohol injections for blind painful eyes. ${ }^{37}$ The downwards and inwards position is also advocated for these procedures.

\section{OTHER IMPLICATIONS}

\section{Pain on eye movement of retrobulbar neuritis}

The retrobulbar pain on eye movement described by patients with optic neuritis has been thought to be caused by traction on the pain sensitive $\mathrm{ON}$ sheath. ${ }^{16}$ The deformation of the ON by such movements is highlighted in vivo. Interestingly, this pain is usually maximal on abduction ${ }^{38}$ when the ON, taking up an S-shaped curve, is perhaps most distorted. If the pain were caused by muscle traction on the sheath, adduction, with contraction of the medial rectus, would be expected to be the more painful..$^{16}$

\section{Imaging of orbital tumours}

Given the clear differentiation of orbital tissue compartments using the STIR technique, improved accuracy in the analysis of the location and attachments of some orbital tumours, particularly those whose origin from the optic nerve may influence management decisions, may be possible using MRI in different positions of gaze. Based on this information, a more accurate prognosis may be given to the patient, and the most appropriate surgery planned.

\section{Gaze evoked amaurosis}

In some orbital tumours, especially cavernous haemangioma ${ }^{39+0}$ and optic nerve sheath meningioma, "transient monocular loss of vision on sustained gaze in a given direction is a well recognised feature. ${ }^{+2+3}$ The large excursion of the optic nerve around such tumours may result in compromise of the haemodynamics of the $\mathrm{ON}$, resulting in momentary and reversible amaurosis in certain gaze positions. ${ }^{+}$

\section{Assessment of extraocular muscle thickness}

A fifth application relates to thickening and thinning of the extraocular muscles when the eyes are not in the primary position. Knowledge of this effect is important when assessing muscle thickness in suspected cases of dysthyroid eye disease and orbital pseudotumours. Although the patient is usually asked to look straight ahead when the orbits are being scanned, this does not always happen. Since a number of mass lesions can also cause expansion of an extraocular muscle, imaging in different positions of gaze may assist differential diagnosis.

We are grateful for the support given to the NMR research group by the Multiple Sclerosis Society of Great Britain and Northern Ireland. We thank Mr David MacManus for his technical guidance, Miss Sue Moore for the operation of the scanner, and Dr Raj Kapoor for helpful discussions. Thanks are also due to Jane Kapoor for helpful discussions. Thanks are also due to Jane Eye Hospital for help with the illustrations.

1 Steele A. Local anaesthesia for cataract surgery. [Editorial] $\mathrm{Br}$ Ophthalmol 1990; 74: 195 .

2 Antoszyk AN, Buckley EG. Contralateral decreased visua acuity and extraocular muscle palsies following retrobulbar anesthesia. Ophthalmology 1986; 93: 462-5.

3 Morgan CM, Schatz H, Vine AV, Cantrill HL, Davidorf FH, Gitter KA, Rudich R. Ocular complications associated with retrobulbar injections. Ophthalmology 1988; 95: 660-5.

4 Pautler SE, Grizzard WS, Thompson LN, Wing GL. Blindness from retrobulbar injection into the optic nerve. Ophthalmic Surg 1986; 17: 334-7.

5 Feibel RM. Current concepts in retrobulbar anesthesia. Surv Ophthalmol 1985; 30: 102-10.

6 Brod RD. Transient central retinal artery occlusion and contralateral amaurosis after retrobulbar anesthetic injection. Ophthalmic Surg 1989; 20: 643-6.

7 Nicholl JM, Acharya PA, Ahlen K, Baguneid S, Edge KR. Central nervous system complications after 6000 retrobulbar blocks. Anesth Analg 1987; 66: 1298-302.

8 Atkinson WA. Retrobulbar injection of anesthetic within the muscular cone (cone injection). Arch Ophthalmol 1936; 16 494-503.

9 Atkinson WS. Local anesthesia in ophthalmology. Am Ophthalmol 1948; 31 : 1607-18.

10 Friedberg HL, Kline OR. Contralateral amaurosis after retrobulbar injection. Am f Ophthalmol 1986; 101: 688-90.

11 Unsöld R, Stanley JA, De Grout J. The CT-topography of retrobulbar anaesthesia. Graefes Arch Klin Ophthalmol 1981; 217: $125-36$

12 Smiddy WE, Michels RG, Kumar AJ. Magnetic resonance imaging of retrobulbar changes in optic nerve position with imaging of retrobulbar changes in optic nerve position

13 Nishida $Y$, Nishida E, Kani K, Inatomi A. The observation of eye movement using magnetic resonance imaging. In: Strabismus and ocular motility disorders. Proceedings of the Sixth Meeting of the International Strabismological Association. Campos EC, ed. London: MacMillan 1991: 137-42.

14 Johnson G, Miller DH, MacManus D, Tofts PS, Barnes D, du Boulay EPGH, et al. STIR sequences in NMR imaging of the optic nerve. Neuroradiology 1987; 29: 238-45.

15 Reeh MJ, Wobig JL, Wirtschafter JD. Ophthalmic anatomy. San Francisco: American Academy of Ophthalmology, 1981: 167-73.

16 Warwick $R$. Wolffs anatomy of the eye and orbit. 7th Ed. London: H K Lewis, 1976: 325-8.

17 Sevel D. The origins and insertions of extraocular muscles: development, histological features, and clinical significance. Trans Am Ophthalmol Soc 1986; 84: 488-526.

18 Drysdale DB. Experimental subdural retrobulbar injection of anesthetic. Ann Ophthalmol 1984; 16: 716-8.

19 Kobet KA. Cerebral spinal fluid recovery of lidocaine and bupivacaine following respiratory arrest subsequent to retrobulbar block. Ophthalmic Surg 1987; 18: 11-3.

20 Rodgers R, Orellana J. Cranial nerve palsy following retrobulbar anaesthesia. Brf Ophthalmol 1988; 72: 78.

21 Follette JW, LoCascio JA. Bilateral amaurosis following unilateral retrobulbar block. Anesthesiology 1985; 63: unilate

22 Javitt JC, Addiego R, Friedberg HL, Libonati MM, Leahy JJ. Brain stem anesthesia after retrobulbar block. Ophthal Brain stem anesthesia

23 Ahn JC, Stanley JA. Subarachnoid injection as a complication of retrobulbar anesthesia. Am F Ophthalmol 1987; 103: 225

24 Straus JG. A new retrobulbar needle and injection technique. Ophthalmic Surg 1988; 19: 134-9.

25 Yanoff M, Redovan EG. Anterior eyewall perforation durin subconjunctival cataract block. Ophthalmic Surg 1990; 21 : 362-3.

26 Joseph JP, McHugh JDA, Franks WA, Chignell AH. Perforation of the globe - a complication of peribulba anaesthesia. Brf Ophthalmol 1991; 75: 504-5.

27 Duker JS, Belmont JB, Benson WE, Brooks HL Jr, Brown 
GC, Federman JL, et al. Inadvertent globe perforation during retrobulbar and peribulbar anesthesia. Patien characteristics, surgical management, and visual outcome. Ophthalmology 1991; 98: 519-26.

28 Hansen EA, Mein CE, Mazzoli R. Ocular anesthesia for cataract surgery: a direct sub-Tenon's approach. Ophthalmic Surg 1990; 21: 696-9.

29 Bruck LB. Needle could reduce retrobulbar risks. Ophthalmology Times 1988; 13: 1 and 21.

30 Buttery $R$, Wise G. Conal anaesthesia: a new approach to retrobulbar anaesthesia. Aust N Z F Ophthalmol 1989; 17:

1 Smith RJH. Why retrobulbar anaesthesia? [Editorial] $\mathrm{Br} \mathcal{F}$ Ophthalmol 1988; 72: 1 .

32 Smith R. Cataract extraction without retrobulbar anaesthetic injection. BrF Ophthalmol 1990; 74: 205-7.

33 Redmond RM, Dallas NL. Extracapsular cataract extraction under local anesthesia without retrobulbar injection. $\mathrm{Br} F$ Ophthalmol 1990; 74: 203-4.

34 Lichter PR. Avoiding complications from local anesthesia. Editorial] Ophthalmology 1987; 94: 565-6.

35 Jaffe NS, Jaffe MS, Jaffe GF. Cataract surgery and its complications, 5th Ed. St Louis: Mosby, 1990: 39.

36 Helveston EM, Pogrebniak AE. Treatment of acquired nystagmus with botulinum A toxin. Am $\mathcal{F}$ Ophthalmol 1988; 106: 584-6.

37 Ellis PP. Retrobulbar injections. Surv Ophthalmol 1974; 18 425-30.

38 Russell RWS. Symptomatology of optic neuritis. Bull Soc Belge Ophtal 1983; 208: 127-30.

39 Unsöld R, Hoyt WF. Blickinduzierte monokulare Obskurationen bei orbitalem Hämangiom. Klin Monatsbl Augenheilkd 1979; 174: 715-21.

40 Brown GC, Shields JA. Amaurosis fugax secondary to presumed cavernous haemangioma of the orbit. Ann presumed cavernous haemangioma of the orbit. Ann

41 Wright JE. Primary optic nerve meningiomas: clinical presentation and management. Trans Am Acad OphthalmolOtolaryngol 1977; 83: 617-25.

42 Orcutt JC, Tucker WM, Mills RP, Smith CH. Gaze-evoked amaurosis. Ophthalmology 1987; 94: 213-8.

43 Bradbury PG, Levy IS, McDonald WI. Transient uniocula visual loss on deviation of the eye in association with intraorbital tumours. F Neurol Neurosurg, Psychiat 1987; 50: 615-9.

44 Knapp MEP, Flaharty PM, Sergott RC, Savino PJ, Mazzoli MD, Flanagan JC. Gaze-induced amaurosis from central retinal artery compression. Ophthalmology 1992; 99: 238-40. 